\title{
DARREL Can Dangerous Climate Change Be Avoided?
}

\begin{abstract}
This article discusses obstacles to overcoming dangerous climate change. It employs an account of dangerous climate change that takes climate change and climate change policy as dangerous if it imposes avoidable costs of poverty prolongation. It then examines plausible accounts of the collective action problems that seem to explain the lack of ambition to mitigate. After criticizing the merits of two proposals to overcome these problems, it discusses the pledge and review process. It argues that pledge and review possesses the virtues of encouraging broad participation and of providing a procedural safeguard for the right of sustainable development. However, given the perceptions of the marginal short term costs of mitigation, pledge and review is unlikely, at least initially, to issue in an agreement to make deep reductions in greenhouse gas emissions. Because there is no rival approach that seems likely to better instantiate the two virtues, pledge and review may be the best available policy for mitigation. Moreover, recent economic research suggests that the co-benefits of mitigation may be greater than previously assumed and that the costs of renewable energy may be less than previously calculated. This would radically undermine claims that the short term mitigation costs necessarily render mitigation irrational and produce collective action problems. Given the circumstances, pledge and review might be our best hope to avoid dangerous climate change.
\end{abstract}

Keywords: Dangerous Climate Change, The Right to Sustainable Development, Pledge and Review, Collective Action Problems

'We live forward...Success and failure are the primary 'categories' of life; achieving of good and averting of ill are its supreme interests; hope and anxiety...

[are the] dominant qualities of experience.'

- John Dewey, The Need for a Recovery of Philosophy

The pace of international climate negotiations has been excruciatingly slow. Although the risks of anthropogenic climate change have been a matter of international record since at least 1988 , negotiators have failed to produce an international framework that has effectively reduced the emissions of greenhouse gases. On the contrary, except for falling slightly in 2009 due to the global recession, global CO2 emissions continue to increase. ${ }^{1}$ In 1992, when the United Nations Framework Convention on Climate Change was signed, the atmospheric concentration of $\mathrm{CO} 2$ was less than 36oppm. In April of 2015 it

1 United States Energy Information Administration (USEIA), <http://www.eia.gov/cfapps/ipdbproject/iedindex3.cfm ?tid=90\&pid=44\&aid=8\&cid=regions\&syid=2007\&eyid=2012\&unit=MMTCD $>($ Accessed 11 May, 2015) 
was $403 \mathrm{ppm} .{ }^{2}$ A 12 percent increase over this period, despite the well-known risks of hardships and catastrophes due to climate change, suggests profound dysfunction in the international response to climate change.

The policy approach to mitigation that has been in favor since the Copenhagen meeting of the Conference of the Parties, COP 15, of the UNFCCC involves states developing mitigation reduction targets separately and in isolation rather than through a process of diplomatic give and take. These targets are to be incorporated into an international agreement as pledges subject to periodic reviews. These pledges are often referred to as intended nationally determined contributions (INDCs) ${ }^{3}$. The currency in which they are offered is percent reductions of $\mathrm{CO} 2$ emissions measured against a chosen baseline year that varies with each state. Analysis of the COP 16 pledges suggests that they are unambitious. According to the AR5, 'The Cancún Pledges are broadly consistent with cost-effective scenarios that are likely to keep temperature change below $3^{\circ} \mathrm{C}$ relative to preindustrial levels.' ${ }^{4}$ In anticipation of COP 21 in Paris in 2015 many states publicly stated the INDCs that they would commit to as part of a new international mitigation framework. A study prior to COP 21 based on the INDCs of the USA and the EU and the expected INDC of Chinathe three largest emitters, accounting for 45 percent of all emissions-as well as the previous pledges of all other countries revealed a lack of ambition to reduce emission sufficiently to limit mean global temperature increase to $2^{\circ} \mathrm{C} .5$ This is corroborated by other analyses. ${ }^{6}$

There is, then, considerable anxiety that an international mitigation regime will not avoid dangerous climate change. This article discusses the obstacles to overcoming dangerous climate change. Any such discussion requires an account of what dangerous climate change is. The only plausible identificatory account of dangerous climate change is normative. I rely on an account I set out in The Moral Challenge of Dangerous Change: Values, Poverty, and Policy. ${ }^{7}$

2 National Oceanic and Atmospheric Administration, Earth Systems Research Laboratory, 'Trends in Atmospheric Carbon Dioxide', <http://www.esrl.noaa.gov/gmd/ccgg/trends/> (Accessed 13 May 2015).

3 'United Nations Framework Convention on Climate Change, Report of the Conference of the Parties on its nineteenth session, held in Warsaw from 11 to 23 November 2013', <http://unfccc.int/resource/docs/2013/cop19/eng/10ao1. pdf> (Accessed 11 May 2015).

4 IPCC, Working Group III: Summary for Policymakers, p. 12.

5 Rodney Boyd, et al., 'What will global annual emissions of greenhouse gases be in 2030, and will they be consistent with avoiding global warming of more than $2^{\circ} \mathrm{C}$ ?', ESRC Centre for Climate Change Economics and Policy, Grantham Research Institute on Climate Change and the Environment, <http://www.lse.ac.uk/GranthamInstitute/wp-content/ uploads/2015/o5/Boyd_et_al_policy_paper_May_2015.pdf> (Accessed 29 May 2015).

6 Climate Action Tracker, 'Emissions Gap - How close are INDCs to 2 and 1.5 ${ }^{\circ} \mathrm{C}$ pathways?', (Sept. 2, 2015), <http:// climateactiontracker.org/news/222/Emissions-Gap-How-close-are-INDCs-to-2-and-1.5C-pathways.html> (Accessed 27 Sept. 2015).

7 Darrel Moellendorf, The Moral Challenge of Dangerous Climate Change: Values, policy and poverty (Cambridge: Cambridge University Press, 2014), ch. 1. 
That account takes climate change and climate change policy as dangerous if it imposes avoidable costs of poverty prolongation. I discuss plausible accounts of the collective action problems that seem to bedevil climate change negotiations and that seem to explain the lack of ambition to mitigate. I then consider the pledge and review process in light of these explanations. Pledge and review possesses two important virtues. First, voluntary pledges should encourage broad participation. Second, pledges made as a result of domestic political processes, and not through diplomatic wrangling, provide a procedural safeguard against poorer, weaker states being put under diplomatic duress. This is perhaps the best safeguard in the circumstances for ensuring the right of sustainable development. Despite these two virtues, given the perceptions of the marginal short term costs of mitigation, pledge and review is unlikely, at least initially, to issue in an agreement to make deep reductions in greenhouse gas emissions. Still there is no rival approach that seems likely to better instantiate the two virtues. Far from ideal, pledge and review may be the best available policy for mitigation. There may be grounds nonetheless to hope for increased mitigation ambition. Recent economic research suggests that the short term benefits of mitigation may be greater than previously assumed, perhaps even sufficient to offset the costs. This would radically undermine accounts that claim that there are collective problems, which render mitigation irrational. Two conclusions seem supported by the above considerations. First, rather than parceling out mitigation burdens so as to achieve the substantive requirements of justice in the assignment of mitigation burdens, pledge and review may approximate justice by procedural means. Second, an agreement lacking in sufficient ambition to avoid dangerous climate change might be strengthened, not primarily by appeal to moral duty, but through the proper recognition of the self-interests of states.

\section{Identifying Dangerous Climate Change}

Mitigation policies seek to stabilize atmospheric concentrations of greenhouse gases so as to limit global mean temperature increase. The consumption of fossil fuels produces significant benefits over the short term, as well as some short-term costs such as pollution-induced morbidity and in some cases uncertain reliance on foreign sources of energy. It also can contribute to longerterm benefits by making possible economic development. The hardships of burning fossil fuels, which fall mostly on people in the future, establish the reasons to cease that activity. The moral significance of these hardships can be conceived in at least two different ways. One way is to see fossil fuel use as generating a problem with regard to the intergenerational distribution of costs. For example, an approach that is standard in the economics of 
climate change counsels the pursuit of mitigation policies that would produce optimal net growth (minus the costs) across generations. ${ }^{8}$ One rival to that view seeks to equalize the ratio of costs to benefits across generations. ${ }^{9}$ According to both of these views the moral task of mitigation is to get the right intergenerational distribution of costs. A second way of conceiving of the moral problem that burning fossil fuels causes is to take climate change as excessive if it surpasses a particular threshold of risk imposition. Approaches of this second kind enjoin against catastrophic changes or, more commonly, set the bar lower and seek to prevent dangerous climate change.

The second approach is the dominant one in international negotiations and the one that concerns me in this paper. The objective of the United Nations Framework Convention on Climate Change 'is to achieve...stabilization of greenhouse gas concentrations in the atmosphere at a level that would prevent dangerous anthropogenic interference with the climate system.' ${ }^{10}$ So conceived, the moral point of mitigation is not to get the distribution of intergenerational costs right but to prevent that amount of climate change that we have reason to believe is too risky. This requires a technical understanding of how the risks associated with warming can be reduced, an economic and social understanding of the costs of reducing risks, and a moral judgment about how to strike the balance between reducing risks and incurring various kinds of costs.

Preventing the inflation of risks due to warming requires capping the concentrations of greenhouse gases in the atmosphere because temperature increase varies with atmospheric concentration of greenhouse gases. The greenhouse gas that contributes the most to warming is $\mathrm{CO} 2$. After it is emitted a molecule of $\mathrm{CO}_{2}$ on average resides in the atmosphere hundreds of years. Hence, the atmospheric concentration of $\mathrm{CO} 2$ is best considered as a function of cumulative emissions since the industrial revolution. The policy consequences of this bit of atmospheric chemistry are significant. For any particular level at which the global mean temperature might be stabilized, there is a sum total of all anthropogenic emissions of greenhouse gases going back to the industrial revolution that must not be exceeded. For example, to have a 66 percent chance (or better) of limiting warming to no more than $2^{\circ} \mathrm{C}$

8 Cf. for example William Nordhaus, A Question of Balance: Weighing the options on global warming policies (New Haven \& London: Yale University Press, 2008).

9 For a defense of this view see Darrel Moellendorf, 'Justice and the Intergenerational Assignment of the Costs of Climate Change,' Journal of Social Philosophy 40 (2009), 204-224. The view is modelled using the computing tools provided by Nordhaus in Darrel Moellendorf and Axel Schaffer, 'Equalizing the Costs of Climate Change - An Alternative to Discounted Utilitarianism', (unpublished).

10 'The United Nations Framework Convention on Climate Change Article 2', <http://unfccc.int/files/essential_ background/background_publications_htmlpdf/application/pdf/conveng.pdf> (Accessed 13 May 2015). 
above pre-industrial levels, no more than one trillion tons of carbon (or 3,670 GtCO2) can in total be emitted. ${ }^{11}$ For $3^{\circ} \mathrm{C}$ the total is 1.5 trillion tons. To be clear, these emissions budgets are for the time period that begins with the industrial revolution and ends whenever the temperature target is hit. At the time of this writing more than half of the $2^{\circ} \mathrm{C}$ budget has been used; over 590 billion tons of carbon have been emitted. The trillionth ton would be reached in early May of 2039, and the 1 1/2 trillionth ton in September of 2056. ${ }^{12}$ As I write, these appointments are constantly being rescheduled for earlier dates as global emissions increase.

The long-term goal of a policy that seeks to limit warming at a stable temperature must be to stabilize the concentration of $\mathrm{CO} 2$ in the atmosphere by halting emissions completely. A zero carbon global economy is eventually required to arrest temperature increase. Most immediately, however, global emissions need to peak and begin reducing. Postponing the time at which emissions peak requires a much steeper reduction to stay within the cumulative budget of any temperature goal. The transition to a zero carbon economy might also be eased if technology were produced to remove carbon from the atmosphere on a wide scale. That would allow overshooting the cumulative emission budget and subsequent removal of the carbon from the atmosphere. The idea is that a negative carbon economy would correct for years of carbon profligacy. The historical result would be a net zero carbon economy. ${ }^{13}$ Research into the kind of carbon dioxide removal technology required to achieve this is, however, still very far from yielding results that could be employed.

Mitigation policy aimed at arresting temperature increase must aim ultimately for a transition to a net zero carbon economy, and it seeks to ease that transition by beginning global emissions reductions as soon as possible. It seeks both the long term and the proximate goals in order to reduce the wellknown risks of hardship caused by climate change. The risks of climate change, then, provide reason for an international regime that effects a reduction in greenhouse gas emissions with the aim of an eventual transition to a carbon free global economy-call this 'a reason for mitigation.'

However, a mitigation regime might also impose morally significant costs. Because the engines of the global economy currently run principally on fossil fuels, if climate change mitigation policy results in significantly raising the

11 IPCCC, 'AR5, The Physical Science Basis, Summary for Policy Makers', p. 25.

12 Cf. <http://trillionthtonne.org/> (Accessed 11 May 2015).

13 See United Nations Environmental Programme (UNEP), The Emissions Gap report 2014, <http://www.unep.org/ publications/ebooks/emissionsgapreport2014/portals/50268/pdf/EGR2014_LOWRES.pdf> (Accessed 14 May 2015). See also Intergovernmental Panel on Climate Change (IPCC), Climate Change 2014, Mitigation of Climate Change, Summary for Policymakers, <http://www.ipcc.ch/pdf/assessment-report/ar5/wg3/ipcc_wg3_ar5_ summary-for-policymakers.pdf> (Accessed 16 May 2015), p.12. 
price of energy, such a policy could produce morally significant economic hardships. This is best highlighted by examples. According to the World Bank in 2001 there were 400 million fewer people living in poverty in China than in 1981 . The rate of poverty over that period dropped from 53 to 8 percent. $^{14}$ The evidence suggests that achieving that kind of success in poverty reduction is very energy intensive. In 1981 China emitted in total 1,439.84 million metric tons of $\mathrm{CO} 2$ from the consumption of energy. But by 2001 this had more than doubled to $3,226.52$ million metric tons. Per capita emissions from the consumption of energy increased from 1.44 metric tons in 1981 to 2.54 in 2001. ${ }^{15}$ But the point need not rely on World Bank measures of poverty. Consider another country, South Korea, and another measure, the Human Development Index. In 1980 South Korea's HDI score was 0.63, more or less the same as Panama's; in 2011 it was 0.89, about even with Iceland. ${ }^{16}$ South Korea's total CO2 emissions over that period rose from 131.73 million metric tons to and 650.45 million metric tons. Per capita emissions grew from 3.46 metric tons to 13.34 metric tons. ${ }^{17}$ In other words, per capita emissions nearly quadrupled over the period in which the HDI score moved from that on par with Central America to that on par with Northern Europe. On the basis of these two examples it seems that progress towards eradicating poverty and promoting human development on a large scale necessarily consumes massive amounts of energy.

The International Energy Agency (IEA) has performed a more systematic study of the relationship between energy and human development. The IEA has developed an Energy Development Index (EDI), which measures a country's use of modern energy. The index is a composite of four indices, each equally weighted, measuring household access to electricity, household access to clean cooking facilities, access to energy for public services, and access to energy for productive use. When countries' ranks on the EDI are potted against their rank on the HDI there is a strong correlation. As energy access expands a country's human development improves. ${ }^{18}$ Intuitively this is not a surprising

14 World Bank, 'Fighting Poverty: Findings and lessons from China's success', <http://econ.worldbank.org/WBSITE/ EXTERNAL/EXTDEC/EXTRESEARCH/o,,contentMDK:20634060 pagePK:64165401 piPK:64165026 theSite PK:469382,0o.html> (Accessed 11 May 2015).

15 USEIA.

16 United Nations Human Development Program. <http://www.google.com/publicdata/explore?ds=bqed7l43 oi2r6_\&ctype $=b \& s t r a i l=$ false\&bcs $=d \& n s e l m=s \& m e t \_x=$ indicator_137506\&scale_x $=$ lin\&ind_x $=$ false\&met_ $\mathrm{y}=$ indicator_103606\&scale_y=lin\&ind_y=false\&idim $=$ country:15503:10303:2403:3803\&ifdim =country\&tun it $=$ Y\&pit $=333777600000 \& h l=e n \_U S \& d l=e n \_U S \& i n d=$ false\&icfg\# $!$ ctype $=b \&$ strail $=$ false\&bcs $=\mathrm{d} \& n s e l m=s \& m$ et_x=indicator_137506\&scale_x=lin\&ind_x=false\&met_y=indicator_103606\&scale_y=lin\&ind_y=false\&idim=c ountry:15503:10303:2403:3803:10703\&ifdim=country\&pit=3268440000oo\&hl=en_US\&dl=en_US\&ind=false> (Accessed 11 May 2015).

17 USEIA.

18 International Energy Agency, World Energy Outlook 2012, <http://www.worldenergyoutlook.org/media/ weowebsite/energydevelopment/2012updates/Measuringprogresstowardsenergyforall_WEO2012.pdf> (Accessed 14 May 2015), p. 547. 
result. Energy consumption is, after all, the means by which agriculture is modernized, exports for international trade are manufactured, and roads, hospitals, and schools are built. And, the less expensive the energy, the more quickly human development can proceed.

Unless the costs of renewable energy in the least developed and developing countries falls sufficiently, either by means of market forces or as a result of subsidies, so as to approximate the costs of coal in these areas, investing in renewable energy will come at the opportunity cost of slowing progress in poverty eradication and human development improvement. There are two reasons for an international regime not to hinder the consumption of energy by means of price increases. The first is to continue to benefit persons who are now being benefited by poverty eradication and human development programs; and the second is to reduce the number of those in the future who would otherwise be born into poverty. Call these 'reasons for the consumption of inexpensive energy' or just 'reasons for consumption' for short.

Both the reason for mitigation and the reasons for the consumption of inexpensive energy seem morally mandatory. Generally policy should not impose severe hardships on people, either through allowing greenhouse gas emissions or hindering homegrown efforts to eradicate poverty. Can these demands be reconciled? A plausible interpretation of the requirements of respect for the inherent dignity of persons, which is assumed in major human rights documents, is that persons must be regarded as co-authors of a common social life. I suggest that the ideal of co-authorship entails that institutions and policies may not be imposed upon people if they are based on principles, which could be reasonably rejected. But it would seem to be reasonable to reject any principle that contradicts either the reason for mitigation or the reasons for consumption. In light of the tension between the reasons for mitigation and consumption, we might wonder whether there is a principle for guiding international energy policy that satisfies what Derek Parfit calls the unanimity condition, namely a principle to which everyone would have sufficient reason to consent. ${ }^{19}$ Without such a principle, we would seem to be faced with a fundamental moral conflict in energy policy.

Everyone has reason to avoid involuntary poverty. The imposition of involuntary poverty by means of policy is an affront to human dignity. Hence, a principle that requires choosing from among available policy options the one that least hinders poverty eradication holds the promise of being a principle that cannot be reasonably rejected by persons seeking agreement on the basis of the value of human dignity. That consideration supports the

19 Derek Parfit, On What Matters Vol. 1 (Oxford: Oxford University Press, 2011), p. 188. 
following antipoverty principle for the evaluation of whether the social and economic costs of climate change mitigation policies are justified in light of the risks of climate change:

Policies and institutions should not impose any costs of climate change or climate change policy (such as mitigation and adaptation) on the global poor, of the present or future generations, when those costs make the prospects for poverty eradication worse than they would be absent them, if there are alternative policies that would prevent the poor from assuming those costs.

The antipoverty principle identifies a policy as dangerous if there are alternative policies available that hinder less the efforts to eradicate poverty. In picking out dangerous policies the principle applies both to policies permitting climate change and to policies combatting it. ${ }^{20}$

By endorsing the antipoverty principle I do not mean to assume that there are no other important risks associated with climate change, risks that we might have reason to avoid. The antipoverty principle is useful, however, because it resolves the tension between the reasons for mitigation and the reasons for consumption. The identification of dangerous climate change and dangerous climate change policy involves a normative judgment about what people have reason to avoid. By incorporating the claim that everyone has reason to avoid involuntary poverty, the antipoverty principle provides an identification of danger that everyone respecting human dignity has reason to accept.

According to the identificatory account of dangerous climate change that I have been defending, there is a prima facie reason to limit warming because of the well-known risks of climate change amplifying the problems of global poverty by means of devastating tropical storms, droughts, heatwaves, and flooding. In addition to these risks, precaution in response to the uncertainty that surrounds possibly cataclysmic events such as massive methane release from arctic or the collapse of terrestrial ice sheets provides additional reasons for mitigation since these events would be devastating generally, but the poor are especially vulnerable. ${ }^{21}$ This account of danger, however, makes no reference to a particular temperature goal. In contrast the Copenhagen Accord, which was produced at the end of COP 15 in 2009, affirmed the aim of limiting warming to $2^{\circ} \mathrm{C} ;{ }^{22}$ and at the subsequent COP 16 in Cancún, the parties re-affirmed that aim and committed to a subsequent review of the

20 I discuss the antipoverty principle in more detail in Darrel Moellendorf, The Moral Challenge of Dangerous Climate Change: Values, Poverty and Policy (Cambridge: Cambridge University Press, 2014), ch. 1.

21 Cf. Moellendorf (2014), ch. 3 for a defense of a strong precautionary principle.

22 UNFCCC, 'Report of the Conference of the Parties on its fifteenth session, held in Copenhagen from 7 to 19 December 2009'. <http://unfccc.int/resource/docs/2009/cop15/eng/11a01.pdf> (Accessed 13 May 2015). 
science to consider whether the goal of limiting warming to $1.5^{\circ} \mathrm{C}$ would be more appropriate. ${ }^{23}$ More recently some commentators have been advocating a switch to a target employing a greenhouse gas concentration limit rather than a temperature target in part because there is less elasticity between policies and concentrations than there is between policies and temperatures. This is due to uncertainties about the feedbacks of increasing concentrations. ${ }^{24}$

Regardless of whether policymakers prefer temperature targets or concentration targets, any particular target should be judged in light of whether greater mitigation would require policies that would prolong poverty. The antipoverty principle seeks the maximal mitigation effort consistent with policies that would not hinder national development policies. If the temperature increase could be limited to $1.5^{\circ} \mathrm{C}$ without requiring policies that constrain poverty eradication, then $2^{\circ} \mathrm{C}$ is too high. In comparing targets it is crucial to be aware of the various costs to the poor that might be imposed by a mitigation proposal focused only on a temperature limit. One cost is the increased absolute cost of energy generation, if a price is put on carbon. Increased energy costs threaten to slow human development and poverty eradication projects by raising their price tag. Another cost is an increase in food prices if agricultural production is directed more towards bio-fuels. ${ }^{25}$ That threatens increased hunger. A third cost is the multitude of negative economic effects that would be caused if a sharp decrease in emissions in the developed countries were to lead to a recession. The effects of the Great Recession begun in 2008, and still ongoing in some regions, demonstrate that recessions in the developed world create profound hardships in developing countries. The economic crisis was transmitted to poor countries through several channels, including a reduction of foreign direct investment, decreased remittance transfers, and reduced demand for basic commodities. The Great Recession was deeply detrimental to human wellbeing in developing and least developed countries. ${ }^{26}$ This experience is important to recall when considering mitigation proposals that call for hitting targets by means of degrowth in the

23 UNFCCC, 'Report of the Conference of the Parties on its sixteenth session, held in Cancun from 29 November to 10 December 2010', <http://unfccc.int/resource/docs/2010/cop16/eng/o7a01.pdf\#page=2> (Accessed 14 May 2015). ${ }_{1.5} \mathrm{C}^{\circ}$ would be a remarkably ambitious goal. The Intergovernmental Panel on Climate Change (IPCC) Working Group III on mitigation does not summarize any mitigation modelling consistent with being likely to achieve that goal.

24 Mike Hulme, 'On the “Two Degree” Climate Policy Target', in Ottmar Edenhofer, et al. (eds.), Climate Change, Justice and Sustainability: linking climate and development policy (Dordrecht: Springer, 2012), pp. 122-125.

25 See Nuffield Council on Bioethics, 'Biofuels: Ethical Issues', (2011), <http://nuffieldbioethics.org/wp-content/ uploads/2014/07/Biofuels_ethical_issues_-chapter5.pdf> (Accessed 14 May 2015), ch. 5.

26 According to a 2010 World Bank report: 'as a result of the food, fuel and financial crises, 64 million more people are living in extreme poverty in 2010, and some 40 million more people went hungry last year. By 2015, 1.2 million more children under five may die, and about 100 million more people may remain without access to safe water', World Bank, 'Flash Note: World Bank Redoubles Help to Countries to Achieve 2015 MDGs' (13 Sept. 2010), <http://web. worldbank.org/WBSITE/EXTERNAL/COUNTRIES/AFRICAEXT/o,,contentMDK:22699344 menuPK:258658 pa gePK:2865106 piPK:2865128 theSitePK:258644,oo.html>. 
industrialized world. ${ }^{27}$ Recessionary experience suggests that such degrowth would lead to massive hardship in the developing and least developed world.

\section{Why Have Mitigation Efforts Been so Limited?}

The risks of unmitigated climate change have been recognized by world leaders for decades. And major economic studies have long forecasted that, when costs and benefits are measured over a period of several decades, substantial global savings result from a policy of mitigation. William Nordhaus, for example, claims that, 'The optimal policy has a very substantial gain in net economic welfare totalling $\$ 3.4$ trillion. $^{\text {'28 }}$ But international negotiations have thus far failed to arrest the growing concentration of greenhouse gases in the atmosphere. Why has the negotiation process failed in the task that is its central objective? Plausible explanations would seem to involve some kind of collective action problem.

It is common now to consider climate change as a kind of tragedy of the commons problem along the lines made famous by Garrett Hardin. ${ }^{29}$ The sum of individual acts of consumption of a good held in common may produce an outcome that is best for no one because the resource is eventually depleted, even though each person sees a compelling reason to continue to consume. In the case of climate change mitigation the tragedy of the commons explanation has roughly the following form:

1. A climate system stabilized approximately as it has been over the Holocene period is a global common good, which benefits every state.

2. The maintenance of that common good requires that some threshold number of states assume net mitigation costs over the medium term.

3. If other states assume costs sufficient to stabilize the climate system, then, for any given state, there is sufficient reason not to assume a share of the net short- to medium-term costs.

4. If others states do not assume costs sufficient to stabilize the climate system, then, for any given state, there is sufficient reason not to assume a share of the net short- to medium-term costs.

5. Hence, for any given state, although the maintenance of a stable

27 Cf. Kevin Anderson, ‘Avoiding "Dangerous" Climate Change Requires Degrowth Strategies from Wealthier Nations' (unpublished), <http://kevinanderson.info/blog/avoiding-dangerous-climate-change-demandsde-growth-strategies-from-wealthier-nations/> (Accessed 15 May 2015). That argument is based the following earlier paper: Kevin Anderson and Alice Bows, 'Beyond 'Dangerous' Climate Change: Emission scenarios for a new world', Philosophical Transactions of the Royal Society A 369 (2011), 20-44. The degrowth position is popularized by Naomi Klein, This Changes Everything: Capitalism vs. The Climate (New York: Simon \& Schuster Press, 2014), ch. 2.

28 William Nordhaus, A Question of Balance: Weighing the options on global warming policies (New Haven \& London: Yale University Press, 2008), p. 84.

29 Garrett Hardin, 'The Tragedy of the Commons', Science 162 (1968), 1243-1248. 
climate system is beneficial, no matter what other states do, there is sufficient reason not to assume a share of the net medium term costs.

The explanation employing the framework of the tragedy of the commons is plausible insofar as there are marginal net costs over the medium-term for states making a transition to the widespread use of renewable energy. In that case, although each state has good reason to have a stable climate system maintained, it may be the case that no state has sufficient reason to assume the costs of maintaining it by means of mitigation.

In principle one way that a tragedy of the commons can be resolved is by the distribution and privatization of the resource threatened with overconsumption, thereby limiting legally permissible use of the property by each party. Private ownership also establishes an incentive for a party to preserve the resource for the enjoyment of long-term consumption. But this approach is not available to countries and the climate system because the climate system cannot be parceled out. Another way that the tragedy can be resolved is through the regulation of the use of the common resource. Typically that involves a strong, independent, and central authority with the means to make credible threats to sanction those who would contravene the regulations for use. This could provide with sufficient reason to cooperate in preserving the resource rather than depleting it. Such an authority could come to be if a sufficient number of the parties took steps towards organizing a common regulatory body that imposed the credible threat of cost imposition on parties, thereby increasing the costs of not complying with conservation. Solving collective action problems of this sort requires overcoming the enormous practical difficulties of getting enough parties moving in the direction of accepting an integrated, central authority, which can make credible threats of that kind.

Why has no central authority arisen from decades of climate negotiations? The banal answer is, of course, that too many countries in a position to lead have not been sufficiently motivated to establish such an authority. The analysis might stop there with the charge of a moral failing. Leaders of countries have failed in their duties to members of future generations. This is sometimes too simple a judgment. One reason for that is that treaties must be not merely signed but ratified, and the latter usually involves the domestic political process to a considerable extent. In democratic societies, legitimacy is conferred on a ratified treaty. Leaders negotiating treaties will find it difficult to promise more than they reasonably believe their citizens will endorse. So, the moral judgment often should be levelled against the countries and not just their leaders. In any case, moral judgment, even when appropriate, is not explanation. And 
without an adequate explanation there seems little hope for progress. If moral motivation has not been sufficient for countries to act, it seems doubtful that bare moral condemnation, even if appropriate, will be either.

Robert O. Keohane and David G. Victor argue plausibly that several aggravating factors have prevented the rise of a central authority that would solve the tragedy of the commons in the case of climate change mitigation. These include the following: 1) A wide distribution of interests among the states involved in negotiations; 2) uncertainty among the states about the risks to which they are exposed and about the benefits of cooperation; 3) a lack of linkages between states that would provide incentives to mitigate; 4) the diversity of problems that constitute climate change, including mitigation, adaptation, and others; and 5) the political difficulties of effecting a transition to renewable energy, especially where state capacity to regulate is weak and international cooperation is not robust. ${ }^{30}$ Victor also argues that several other contingent features of the negotiations have prevented the establishment of an ambitious and effective mitigation treaty. Climate negotiations with a large number of parties, where decision making is based on the norm of unanimous consent, encourages unambitious proposals. ${ }^{31}$ Since governments are usually not the emitters, and because the level of emissions is sensitive to several factors beyond a government's direct control, there is some reluctance to impose ambitious reduction goals. ${ }^{32}$ The lack of full control over the factors involved in reducing emissions has also encouraged flexibility in targets and a reticence to make legally binding commitments for steep emissions reductions.

Additionally Victor contends that because national regulatory regimes vary widely, and absent a comprehensive cap and trade policy within a state, negotiators find it difficult to negotiate ambitious reductions with confidence that domestic policy will be appropriately fine-tuned to hit the cap accepted in the international agreement. ${ }^{33}$ Ease in hitting the target might be facilitated by means of an international scheme of emissions credit trading, but, Victor claims, variations of domestic policy produce widely varying prices on carbon emissions that could not survive in an international market for emissions. Once again, domestic policies frustrate international integration. ${ }^{34}$

While not rejecting the tragedy of commons analysis altogether, Stephen

30 Robert O. Keohane and David G. Victor, 'The Regime Complex for Climate Change', Perspectives on Politics 9 (2011), 12-13.

31 David G. Victor, Global Warming Gridlock (Cambridge: Cambridge University Press, 2011), p. 213.

32 Ibid., pp. 215-216.

33 Ibid., pp. 74-75.

34 Ibid., pp. 77-80. 
M. Gardiner offers an alternative, novel account of the collective action problem that takes the actors to be generations rather than states. Intergenerational problems exists when a current generation would have to assume net costs in order to act in ways that bring net benefits to subsequent generations. In such cases there is an incentive to pass the buck to subsequent generations. ${ }^{35}$ In the case of climate change the structure of the problem takes approximately the following form:

1. Each generation has reason to have earlier generations assume mitigation costs in order to preserve a stable climate system, approximately as it has been over the Holocene period.

2. If for any earlier generation, acting to prevent the destabilization of the climate system requires incurring net costs, then it has insufficient reason to assume the costs.

3. For any earlier generation acting to prevent the destabilization of the climate system requires incurring net costs.

4. Hence, for any for any earlier generation, although it has reason to have earlier generations assume mitigation costs in order to preserve a stable climate system, it has insufficient reason to assume the costs of stabilizing the climate system.

The great practical difficulty of the intergenerational problem is that it is not possible for subsequent generations to establish a coercive authority that would provide earlier generations with sufficient reason to comply with intergenerational projects. The result, according to Gardiner, is 'the tyranny of the contemporary. ${ }^{36}$ He seems to suggest that this sort of collective action problem offers the best explanation of why states have lacked so much ambition in developing an international climate change mitigation regime. 'This would explain why they are willing to take small, cautious steps that can be reviewed on a decade-by-decade basis. For taking low-cost measures to slow down the warming (as opposed to arresting it) is strongly in the interests of those who may be around for another twenty to forty years.' ${ }^{37}$ Indeed, Gardiner claims that 'the presence of temporal dispersion threatens to undercut the very motivation of countries to act' and that that 'is the real global warming tragedy.' ${ }^{38}$ According to Gardiner's explanation, if there is to be a solution to the collective action problem, normative argumentation and changed motivation based upon such argumentation will play a large role. People have

\footnotetext{
35 Stephen M. Gardiner, A Perfect Moral Storm: The Ethical Tragedy of Climate Change (Oxford: Oxford University Press, 2011), p. 36.

36 Ibid., ch. 5 .

37 Stephen M. Gardiner, 'The Global Warming Tragedy and the Dangerous Illusion of the Kyoto Protocol', Ethics and International Affairs 18 (2004), p. 37.

38 Gardiner (2011), p. 125.
} 
to be convinced that their moral duty to future generations trumps their interest in consuming fossil fuels, and institutions based on that conviction must be designed and built.

The claim that the real global warming tragedy is an intergenerational problem seems to mean that that the intergenerational problem has more explanatory power than the tragedy of commons, that it better accounts for the failure to mitigate. Given the great difficulties in solving the intergenerational problem this is a sobering thought. For present purposes we do not need to solve the matter of which account best explains mitigation failure. It is enough to notice that the problem in both cases arises because, even though it is widely recognized that stabilizing the climate system is beneficial, there are insufficient reasons to assume the costs over the short- to medium-term of stabilizing the system. This is explicit in premises 3 and 4 of the explanation based on the tragedy of the commons. Regardless of what other states do, no state has sufficient reason to assume the net costs of climate change mitigation. It is also explicit in premises 2 and 3 of the explanation by means of the intergenerational problem. Because mitigating climate change requires a generation incurring net costs on behalf of subsequent generations, no generation has sufficient reason to mitigate. We shall return to the plausibility of the claim that there are such net costs in section 4 . But for now we assume that to be the case and we turn to proposals for the solutions to these problems.

\section{Policy Proposals for Overcoming the Collective Action Problems}

In order to solve the problems of incentivizing states Victor proposes a club model that begins, not with all of the parties of the UNFCCC, but with a small group of the willing. He suggests that the development of a climate change mitigation regime should be modelled roughly on the development of the international trade regime. It starts with a small group of states, which see an advantage in coming together to mitigate climate change. 'When negotiations are complex there is a strong premium on starting with a small number of countries that matter most.' 39 This responds in two ways to the problems that he has identified. First, in the negotiations among motivated parties, the interest in defecting is less. Second, a smaller motivated group is far more likely to produce robust emissions reductions than is a large body, whose members have very divergent interests in climate change policy. Ambition to mitigate may be encouraged by making significant promises contingent on what other parties propose. That builds the trust necessary to overcome the collective action problem.

39 Victor (2011), p. 242. 
Victor imagines a process in which mitigation obligations are freely assumed, primarily on the basis of the interests of states. Some states that are enthusiastic about climate change will cooperate to trade of emission entitlements and to establish mechanisms of gaining credit by financing low and no carbon energy generation in developing countries, thereby bringing other members into the club. The main incentives driving this process would be market access to the emissions entitlements and access to markets in infrastructure and development assistance. But there are also the benefits that vary by state, which are negotiated upon ascension to the club. Ultimately, however, as mitigation becomes more difficult and greater assurances would be required to keep the club together, punitive measures for non-compliance, such as trade sanctions, would become necessary.

The principal drawback of Victor's proposal is the complexity of the process that would eventually bring about substantial progress in mitigation. The proposal foresees complex negotiations, which can become protracted. Victor's favorite analogy, the WTO, demonstrates this point. There were 47 years between the founding of the GATT in 1948 and its dissolution into the WTO in 1995. Negotiating rounds within the WTO have been enormously complicated. Since the advent of the Doha Round in 2001 progress has been slow or stalled. Climate change mitigation does not enjoy that kind of luxury with respect to time. Given the urgency of capping global emissions, the process of developing and implementing an effective climate change mitigation framework must proceed at a pace considerably quicker than that of trade negotiations. If Victor is correct about how the collective action problem must be overcome, the news is not particularly welcome, since it seems unlikely that the process he advocates can accommodate the urgency.

An institutional solution to the intergenerational problem requires a means by which the interests of subsequent generations are given sufficient voice to hold previous generations accountable. Developing the right sort of institutions requires first establishing sufficient moral resolve to take seriously the interests of future generations and second intelligent institutional design that would satisfactorily represent those interests. Gardiner offers as a proposal for institutional design a global constitutional convention for the purposes of establishing a global constitutional system, which would represent the interests of future generations. ${ }^{40}$ Such a system he takes to be a set of norms regarding 'the limits of government power or authority. ${ }^{41}$ Gardiner says little about the enforcement of these norms. But to be effective, the constitutional system

40 Stephen M. Gardiner, 'A Call for a Global Constitutional Convention Focused on Future Generations', Ethics and International Affairs 28 (2014), 299-316.

41 Ibid., p. 306. 
would need to be able to credibly threaten agents in the present on behalf of the interest of future people. This would require coercive power. If states that acted contrary to the interests of future generations could not be sanctioned, then there would be no reason to think that the constitutional system would be effective in solving the problem.

Gardiner is at pains to distinguish his suggested constitutional convention from a world government, which, he claims, the former would not necessarily produce. But the aim of the convention is to produce a constitutional system. If that system has legal authority backed by the threat of sanction, and if the authority were answerable to the representatives of future persons from regions, rather than states, as Gardiner recommends, then it would be a separate global authority that either usurped power from, or limited the power of, states. It would seem to be a form of global political authority, if not a full blown global state. That may in fact be what is needed to address the intergenerational problem in a robust way, but it would likely find fierce resistance from powerful states that are not keen to give up a domain of authority. This suggests enormous political challenges in implementing the proposal, the significance of which-as with Victor's proposal-is that time is limited.

Setting aside the hurdle to implementing Gardiner's proposal, it is not yet sufficiently developed to judge whether it could function adequately assuming it were implemented. He proposes that the convention should represent generations from different time-periods with an infinite time horizon. ${ }^{42}$ This raises a number of questions about the makeup and functioning of such a convention. How many generations get represented? There cannot be an infinite number of representatives. Perhaps a finite set of representatives of a finite set of generations should take an infinite time horizon as its concern. But then why represent generations at all, if they are not all represented? And would not a concern about an infinite time horizon conflict with a representative acting on behalf of her particular generation? It is also not clear what the decision making mechanism would be. Consensus would seem to be a recipe for gridlock. And, majority rule might frustrate the urgent interests of the minority for the sake of relatively minor concerns of the majority. There are several very big questions, then, with the workability of this proposal. Perhaps additional detailed proposals for the functioning of the convention would be able to answer these questions adequately. But no judgment in favor of the proposal as providing an adequate answer to the intergenerational problem is possible without knowing more about how such a convention could be effective.

Victor's proposal offers a plausible way of solving the collective action problems 42 Ibid., p. 311. 
he analyzes, but it is likely to require a protracted process of implementation. Gardiner's proposal is comparatively underdeveloped and seems to contain both serious obstacles to implementation due to state sovereignty and potential debilitating problems with respect to representation and decision making at the convention. These conclusions are not welcome news for the prospects of mitigating sufficiently to avoid dangerous climate change.

One way to go about hitting a global emissions limit would be to parcel out entitlements to states to emit according to an internationally negotiated plan. In the post-Kyoto Protocol policy environment, that has not been the means used. Since COP 15 the primary tool has been the pledge and review system. States make pledges based upon their perception of what they can accomplish and their expectations of what other states will pledge. At COP 16 the pledges of parties were part of the final, formal agreement. Those pledges are promises to reduce $\mathrm{CO} 2$ emissions by various percentages by 2020.

There are two important virtues of the pledge and review approach. First, the voluntary nature of the process promises widespread participation since each state may contribute to the effort as it sees fit. Second, pledges made as a result of domestic political processes, and not as a result of diplomatic pressure, provide a procedural safeguard against poorer, weaker states being put under diplomatic duress. By ratifying the UNFCCC, states have promised to respect a right to sustainable development. Arguably this is one the most important side-constraints based on considerations of justice to the goal of mitigation climate change. ${ }^{43}$ But insofar as either the tragedy of commons or the intergenerational problem offer plausible explanations for the failure to mitigate climate change, we have good reason to expect that the pledge and review process will yield over-all a fairly small package of emissions reductions. Under pledge and review there is no central authority to establish an incentive for states to mitigate, and there is no institutional means by which subsequent generations can hold the present generation accountable.

\section{Hope for Avoiding Dangerous Climate Change}

The avoidance of dangerous climate change requires both substantial climate change mitigation and a distribution of the costs of mitigation that does not avoidably slow the ongoing process of poverty eradication. The collective action problems discussed in the previous two sections generally provide reasons for anxiety that efforts to mitigate will be weak. However, regardless of whether the failure to mitigate were best explained by the tragedy of commons or the intergenerational problem, the problem would be undermined if climate change mitigation did not necessarily involve assuming net costs,

43 See Moellendorf (2014), ch. 5 . 
either for a state or an earlier generation. There is some indication of such evidence.

Recent work by Nicolas Stern and his colleagues argues that there is good reason to believe that the costs of climate change mitigation over the shortto medium-term do not exceed the benefits in many cases. This is driven primarily by two factors. The first is the falling costs of renewable energy, solar photovoltaic energy in particular. Stern claims that, 'The cost of energy that can be delivered from these devices is competitive (i.e. without the need for subsidies and in the absence of appropriate carbon taxes) in perhaps 80 or so countries.' ${ }^{4}$ How much we can generalize from this about the ability of renewable energy to compete widely in various national markets as a full substitute for fossil fuels is not yet clear. But there are grounds for reasonable hope that the absolute costs of transitioning to renewable energy are declining. Moreover, we are coming to better understand that there are short-term costs of fossil fuels. The high costs of human mortality and morbidity resulting from the particulate matter that is the by-product of burning fossil fuels, especially in quickly developing countries such as China, are now well-established. ${ }^{45}$ There are then important co-benefits of climate change mitigation that can accrue over the short- to medium-term. Very importantly, the combined effect of these two factors may be that there are net benefits resulting from climate change mitigation over the short- to mediumterm in many areas. That would undermine collective action problems of either of the two forms discussed above. If the relative costs of renewable energy seem likely to continue to fall, that would provide reason to believe that a pledge and review policy that initially lacked mitigation ambition could be increased over time. A mitigation agreement that requires periodic revision of the commitments of parties could offer hope of eventually achieving more than the initial commitments.

The collective action problems discussed above could persist, however, even if there were no short- to medium-term costs of mitigation as long as the belief in such costs persisted. We should distinguish between the fact-relative sense of what a party has reason to do and the belief-relative sense. ${ }^{46}$ A party may have reason to do $\mathrm{X}$, if $\mathrm{X}$ would be required by appropriate standards of rationality (whatever these are) in light of all of the facts. Alternatively a party may reason to do $\mathrm{X}$, if $\mathrm{X}$ would be required by appropriate standards of rationality in light of the party's beliefs about the facts. Now, the explanation

44 Nicolas Stern, 'Economic Development and Values: Making policy', Proceedings of the Royal Society B 282 (2015), p. 5 .

45 Ibid., p. 6.

46 Parfit (2011), p. 150 ff 
of action typically invokes agents' beliefs about their interests. Insofar as collective action problems seek to explain mitigation failures, then, what matters is what agents believe. Hence, it could be the case that the collective action problems persist even if Stern's arguments provide genuine insight into the truth of the claim that there are short- to medium-term co-benefits of climate change mitigation. This would be the case, if Stern's arguments were not widely disseminated, understood, and accepted. Education about the co-benefits of mitigation is, then, of immense importance.

An additional concern is that even if there were net benefits of mitigation, rendering a mitigation policy a Kaldor-Hicks improvement over nonmitigation, the distribution of these benefits may create winners and losers. This is important both for morality and for politics. Some of the losers may have claims of justice to be compensated. For example, workers in the coal industry may require retraining. Morally appropriate domestic mitigation policy must adequately respond to such claims. More problematic for effecting a transition to a carbon free economy are the political hurdles. Some losers may be capable of organizing powerful political lobbies that resist change. For example, according to the International Energy Agency no more than one third of the known fossil fuel reserves can be burned prior to 2050 if warming is to be limited to $2^{\circ} \mathrm{C} .{ }^{47}$ The fossil fuel industry is capable of mobilizing well-funded political campaigns against the removal of subsidies for coal and support for renewable energy. This underscores the political importance of campaigns such the fossil fuel divestment movement. Campaigns such as these can also play an educating role in disseminating information about the co-benefits of climate change mitigation.

\section{Conclusion}

It might seem sensible to think that the best hope for mitigation sufficient to avoid dangerous change is an international negotiating process that centrally assigns burdens to states that are both equitable and sufficient as a total package to reduce substantially the risks of climate change, and that yields an institutional structure capable of enforcing those assignments. I, at least, have been tempted by that view. The arguments of this paper suggest that that is not where we should place our hopes. Widespread belief that there are shortto medium-term costs that must be borne in order to mitigate climate change seem to perpetuate collective action problems, which result in a failure of climate change mitigation. But to the extent that mitigation failure can be explained in this way, there is reason to doubt that any diplomatic process

47 International Energy Agency, World Energy Outlook 2012, Executive Summary, <http://www.iea.org/publications/ freepublications/publication/English.pdf> (Accessed 13 Oct. 2015), p. 3. 
pursuing centrally negotiated emissions reductions will deliver results that match the urgent need to mitigate.

The pledge and review process promises widespread participation by states. Moreover, if justice requires protecting the development ambitions of developing and least developed states, this might be best safeguarded not by a diplomatically agreed upon assignment of mitigation burdens, but by a process that permits states to generate their own mitigation goals. Pledge and review does not provide an easy resolution to either the tragedy of the commons or the intergenerational problem. But recent economic research suggests that the facts might contradict the claim that drives these problems, namely that there are net short- and medium-term costs that accrue to parties mitigating climate change. If that claim is false, then progress in avoiding dangerous climate change might best be pursued by convincing parties to act in their interests. ${ }^{48}$

Darrel Moellendorf

Cluster Professor of International Political Theory

Professor of Philosophy

Goethe University, Frankfurt

email: darrel.moellendorf@normativeorders.net

\section{the globaljusticenetwork}

48 I would like to thank Fergus Green, Tamara Jugov, Allen Thompson and Laura Valentini for very helpful comments on earlier versions of this paper. Various versions of this paper were presented to the Instut d'Étude Avancées (Paris); Normative Orders, Goethe-Universität Frankfurt, the Freedom Center, the University of Arizona; the Philosophy Department, the University of Johannesburg; and Humbolt-Universität zu Berlin. I am grateful for the feedback that I received from audiences at each of those venues. 